\title{
Improvement of Science Learning Outcomes of Light Properties Material Through Discovery Learning Model in SD Muhammadiyah Donorejo
}

\section{Sri Sujiyati}

\author{
SD Muhammadiyah Donorejo \\ sujikamto2016@gmail.com
}

\section{Article History \\ accepted 14/11/2020}

approved $21 / 11 / 2020$

\begin{abstract}
This research was motivated by the low learning outcomes of students in science learning grade IV SD Muhammadiyah Donorejo learning year 2020/2021 light properties material. This study aims to improve student learning outcomes and improve teacher performance by using discovey learning models. The implementation of learning improvement research is carried out during two diklus and is carried out through a process of ptk-cycled assessment with four stages (planning, implementation, observation, reflection). From the results of data analysis, the conclusion obtained is that discovery learning models can improve student learning outcomes. This can be seen in the increase in the average asset value of each cycle, at Pre cycle 35\%, Cycle $150 \%$, Cycle 1 I 70\%, and cycle III 90\%. Thus, based on data analysis, the discovery learning model has been successful even though it is not yet perfect.
\end{abstract}

Keywords: Learning outcomes, discovery learning model, science

Abstrak

Penelitian ini dilatarbelakangi oleh rendahnya hasil belajar siswa dalam pembelajaran IPA kelas IV SD Muhammadiyah Donorejo tahun pembelajaran 2020/2021 materi sifat-sifat cahaya. Penelitian ini bertujuan untuk meningkatkan hasil belajar siswa dan meningkatkan kinerja guru dengan menggunakan model pembelajaran Discovey Learning. Pelaksanaan penelitian perbaikan pembelajaran dilaksanakan selama dua diklus dan dilakukan melalui proses pengkajian berdaur PTK dengan empat tahapan (perencanaan, pelaksanaan, observasi, refleksi). Dari hasil analisis data, kesimpulan yang diperoleh adalah model pembelajaran discovery learning dapat meningkatkan hasil belajar siswa. Hal ini dapat dilihat pada peningkatan rata-rata nilai keaktivan setiap siklus, pada Pra siklus $35 \%$, Siklus $150 \%$, Siklus 1 I $70 \%$, dan siklus III $90 \%$. Dengan demikian, berdasarkan analisis data, maka model pembelajaran discovery learning sudah berhasil meski belum sempurna.

Kata kunci: Hasil belajar, model pembelajaran discovery learning, IPA

Social, Humanities, and Education Studies (SHEs): Conference Series https://jurnal.uns.ac.id/shes

p-ISSN 2620-9284 e-ISSN 2620-9292 


\section{PENDAHULUAN}

Masa pandemic Covid-19 menyebabkan berbagai efek dalam setiap aspek kehidupan, termasuk dalam dunia pendidikan. Pembelajaran normal tatap muka tidak bisa lagi laksanakan setiap hari dan banyak wilayah yang melaksanakan pembelajaran melalui jaringan internet. Imbasnya banyak materi pembelajaran tidak tersampaikan dengan maksimal terhadap peserta didik. Apalagi untuk wilayah yang jaringan internet tidak dapat terjangkau dengan kuat.

Selain itu, masalah kemampuan orang tua dalam mendampingi anak-anak belajar di rumah juga masih kurang, karena banyak orang tua yang belum mengerti tentang sistem pendidikan saat ini. Dan juga faktor ekonomi, dimana orang tua harusbekerja sehingga tidak bisa mendampingi anaknya belajar.

Keadaan demikian berpengaruh juga terhadap hasil belajar peserta didik, salah satunya dalam muatan pembelajaran IPA. Pelaksanaan pembelajaran utama hanya menggunakan aplikasi WA yang tidak mendukung tatap muka dengan banyak peserta, kegiatan pembelajaranpun masih berpusat pada guru yang lebih banyak sebagai aplikasi pengirim tugas dan tanya jawab. Dengan kondisi tersebut maka penanaman konsep dalam pembelajaran IPA kurang maksimal.

Berdasarkan hasil observasi di kelas IV SD Muhammadiyah Donorejo, dapat diketahui permasalahan sebagai berikut. Rendahnya nilai peserta didik pada materi sifat-sifat cahaya yang dilihat pada nilai ulangan harian yang belum mencapai KKM yang ditetapkan oleh sekolah yaitu 70. Dari 20 peserta didik terdapat 7 peserta didik (35\%) yang mendapatkan nilai diatas Kriteria Ketuntasan Minimal (KKM) yaitu $\geq 70$, sedangkan sisanya 13 peserta didik $(65 \%)$ mendapatkan nilai dibawah KKM $(\geq 70)$. Rendahnya nilai peserta didik disebabkan dalam pembelajaran khususnya pada materi sifat-sifat cahaya guru hanya menggunakan model ceramah dan penugasan dalam menyampaikan pembelajaran daring. Akibatnya peserta didikpun merasa bosan dengan pembelajaran yang ada dan dalam penyampaian materi guru cenderung bersifat abstrak sehingga peserta didik merasa kebingungan dalam memahami materi yang disampaikan oleh guru. Guru kurang memberikan peluang kepada peserta didik untuk mengkonstruksi sendiri konsep-konsep IPA, peserta didik hanya mengerjakan tugas yang diberikan oleh guru.

Pada pembelajaran IPA peserta didik mempelajari sifat-sifat cahaya tanpa mengetahui maknanya, peserta didik hanya melihat buku atau gambar saja. Pembelajaran IPA masih bersifat abstrak karena ketika menjelaskan guru kurang menggunakan media nyata, pembelajaran IPA yang abstrak ini mudah dilupakan peserta didik, sehingga guru harus mengulang kembali apa yang sudah dipelajari peserta didik sebelumnya.

Khusus bagi peserta didik sekolah dasar yang taraf berfikirnya masih sangat sederhana, untuk dapat menanamkan pemahaman terhadap materi secara baik perlu adanya dukungan benda-benda konkret atau model. Misalnya dalam mengajar pokok bahasan sifat-sifat cahaya pada kelas IV SD Muhammadiyah Donorejo, diperlukan dukungan media pembelajaran dan model yang relevan dengan materi yang akan disampaikan, sehingga dapat meningkatkan hasil belajar IPA tentang sifat-sifat cahaya.

Seorang guru membutuhkan keterampilan mengajar yang lebih dibanding dengan orang yang bukan guru. Guru harus kaya model dan strategi mengajar. Model mengajar adalah suatu teknik penyampaian bahan pelajaran kepada murid, ia dimaksudkan agar murid dapat menangkap pelajaran dengan mudah, efektif dan dapat dicernakan oleh anak dengan baik. Model discovery learning adalah sistem belajar mengajar dimana guru menyajikan bahan pelajaran tidak dalam bentuknya final, tetapi peserta didik yang diberi peluang untuk mencari dan 
menemukannya sendiri dengan mempergunakan teknik pendekatan pemecahan masalah.

Setelah peneliti melihat masalah yang terjadi di SD Muhammadiyah Donorejo, peneliti memiliki alternatif solusi yang tepat untuk memecahkan masalah tersebut yaitu dengan merubah model pengajaran yang selama ini dilakukan. Karena dengan model penugasan ke pada peserta didik kurang maksimal dalam memahami materi yang disampaikan guru dan peserta didik cenderung bosan bahkan tidak mengerjakan tugas sama sekali. Model yang tepat untuk pembelajaran IPA adalah model discovery learning.

Dengan melihat masalah di atas maka penulis merasa tertantang untuk meneliti tentang penerapan model pembelajaran inquiry discovery learning. Maka penulis memberi judul "Peningkatan Hasil Belajar IPA Materi Sifat-Sifat Cahaya melalui Model Discovery Learning pada Peserta didik Kelas IV SD Muhammadiyah Tahun Pelajaran 2020/2021." Dengan penelitian ini diharapkan para guru dapat lebih selektif memilih model mengajar yang tepat dan dapat dipraktikkan oleh peserta didik.

\section{METODE}

Penelitian ini adalah penelitian tindakan kelas (Classroom Action Research) dengan menerapkan model pembelajaran Discovery Learning. Menurut Kurt Lewin dalam Kunandar (2011: 42) penelitian tindakan kelas ini terdiri dari empat tahapan dasar yaitu perencanaan (planning), pelaksanaan (acting), pengamatan (observing) dan refleksi (reflecting). Analisis penelitian ini adalah analisis deskriptif kuantitafif kualitatif dimana dalam penelitian ini selain penyajian hasil berupa data maupun angka peneliti juga menentukan bagaimana cara pengolahan hasil penelitian yakni dengan membuat analisisnya dengan menerapkan model penelitian Discovery Learning. Penelitian ini dilaksanakan pada peserta didik kelas IV SD Muhammadiyah Donorejo Tahun Pelajaran 2020/2021 selama II siklus secara daring menggunakan aplikasi Zoom Meeting dengan satu pertemuan disetiap siklusnya. Siklus I dilaksanakan pada tanggal 16 November 2020. Siklus II dilaksanakan pada tanggal 23 November 2020. Siklus III dilaksanakan pada tanggal 4 Desember 2020. Teknik pengumpulan data yang dilakukan dengan observasi dan tes Evaluasi. Observasi meliputi observasi keterlaksanaan model pembelajaran Discovery Learning, sikap peserta didik dan keterampilan. Untuk hasil belajar menggunakan tes melalui Google form.

\section{HASIL DAN PEMBAHASAN}

Pada Siklus I diperoleh data kualitatif dan kuantitatif, yang termasuk data kualitatif yaitu: lembar keaktivan siswa dan lembar kinerja guru. Sedangkan data kuantitatif yaitu nilai hasil belajar siswa. Nilai hasil belajar siswa diperoleh melalui tes tertulis, instrument tes yang digunakan berupa lembar evaluasi. Data hasil belajar siswa pada siklus I seperti tabel di bawah ini

Tabel 1. Perbandingan Nilai Evaluasi Pra Siklus dengan Siklus I

\begin{tabular}{cccccc}
\hline \multirow{2}{*}{ Predikat } & \multirow{2}{*}{ Nilai } & \multicolumn{2}{c}{ Jumlah Siswa } & \multicolumn{2}{c}{ Prosentase } \\
\cline { 3 - 6 } Pra Sikus & Siklus I & Pra Sikus & Siklus I \\
A & $91-100$ & 0 & 0 & $0 \%$ & $0 \%$ \\
B & $81-90$ & 0 & 2 & $0 \%$ & $10 \%$ \\
C & $71-80$ & 3 & 8 & $15 \%$ & $40 \%$ \\
D & $<70$ & 17 & 10 & $85 \%$ & $50 \%$ \\
Jumlah Siswa & 3 & 10 & & \\
Tuntas & & & & & \\
\hline
\end{tabular}


Berdasarkan tabel di atas dapat dilihat bahwa hasil nilai rata-rata sebelum tindakan hanya $35 \%$. Masih banyak siswa yang belum mencapai nilai kriteria ketuntasan minimal, yaitu sebanyak 13 siswa. Sedangkan yang sudah tuntas dari nilai KKM sebanyak 7 siswa. Setelah adanya Tindakan pada siklus I hasil belajar siswa meningkat $15 \%$ mejadi $50 \%$ siswa yang sudah tuntas. Dari hasil belajar tersebut dapat dinyatakan bahwa hasil belajar IPA siswa kelas IV SD Muhammadiyah Donorejo, Kecamatan Secang, Kabupaten Magelang masih rendah dikarenakan belum mencapai nilai KKM yang telah ditentukan yaitu 70 .

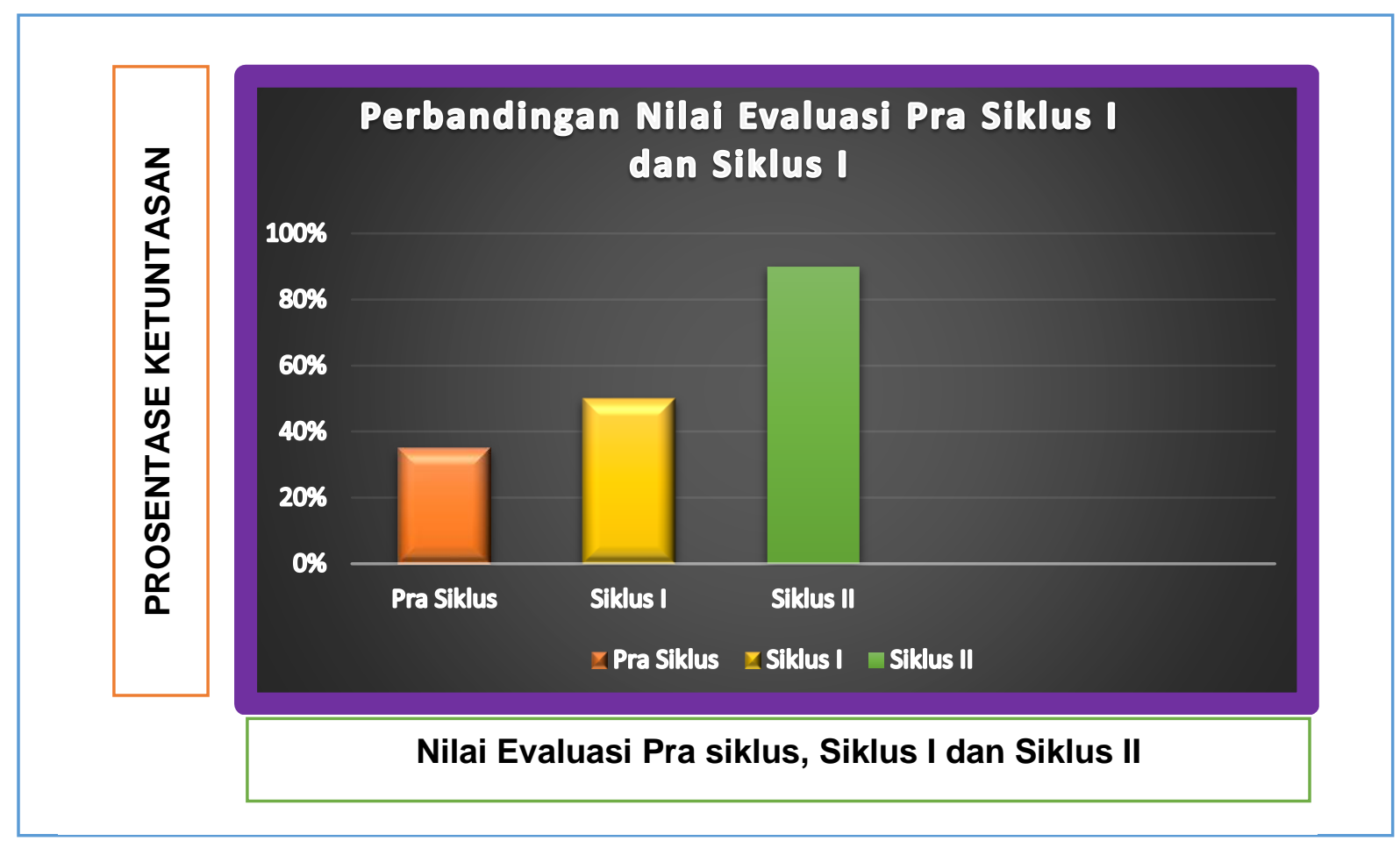

\section{Gambar 1. Perbandingan ketuntasan nilai pra siklus dan siklus 1}

Untuk mengetahui keberhasilan dalam penelitian ini, perlu adanya perbandingan antara nilai hasil evaluasi siklus I dan nilai hasil evaluasi siklus II . Hal ini dapat dilihat pada tabel perbandingan hasil belajar siswa siklus I dan siklus II berikut ini.

Tabel 2. Perbandingan Nilai Evaluasi Siklus I dan siklus II

\begin{tabular}{cccccccc}
\hline \multirow{2}{*}{ Predikat } & \multirow{2}{*}{ Nilai } & \multicolumn{3}{c}{ Jumlah Siswa } & \multicolumn{3}{c}{ Prosentase } \\
& & Pra Sikus & Siklus I & Siklus II & Pra Sikus & Siklus I & Siklus II \\
\hline A & $91-100$ & 0 & 0 & 1 & $0 \%$ & $0 \%$ & $5 \%$ \\
B & $81-90$ & 0 & 2 & 7 & $0 \%$ & $10 \%$ & $35 \%$ \\
C & $71-80$ & 3 & 8 & 6 & $15 \%$ & $40 \%$ & $30 \%$ \\
D & $<70$ & 17 & 10 & 6 & $85 \%$ & $50 \%$ & $30 \%$ \\
Jumlah Siswa Tuntas & 3 & 10 & 14 & $15 \%$ & $50 \%$ & $70 \%$ \\
\hline
\end{tabular}

Berdasarkan data diatas dapat diketahui bahwa pada Pra siklus siswa yang tuntas ada 7 siswa (35\%), siklus I siswa yang tuntas ada 10 siswa (50\%) dan pada siklus II ada $12(60 \%)$ siswa yang tuntas. Dari 
paparan hasil penelitian dari pra siklus sampai pada siklus II di atas diperoleh data nilai hasil belajar siswa sebagai berikut:

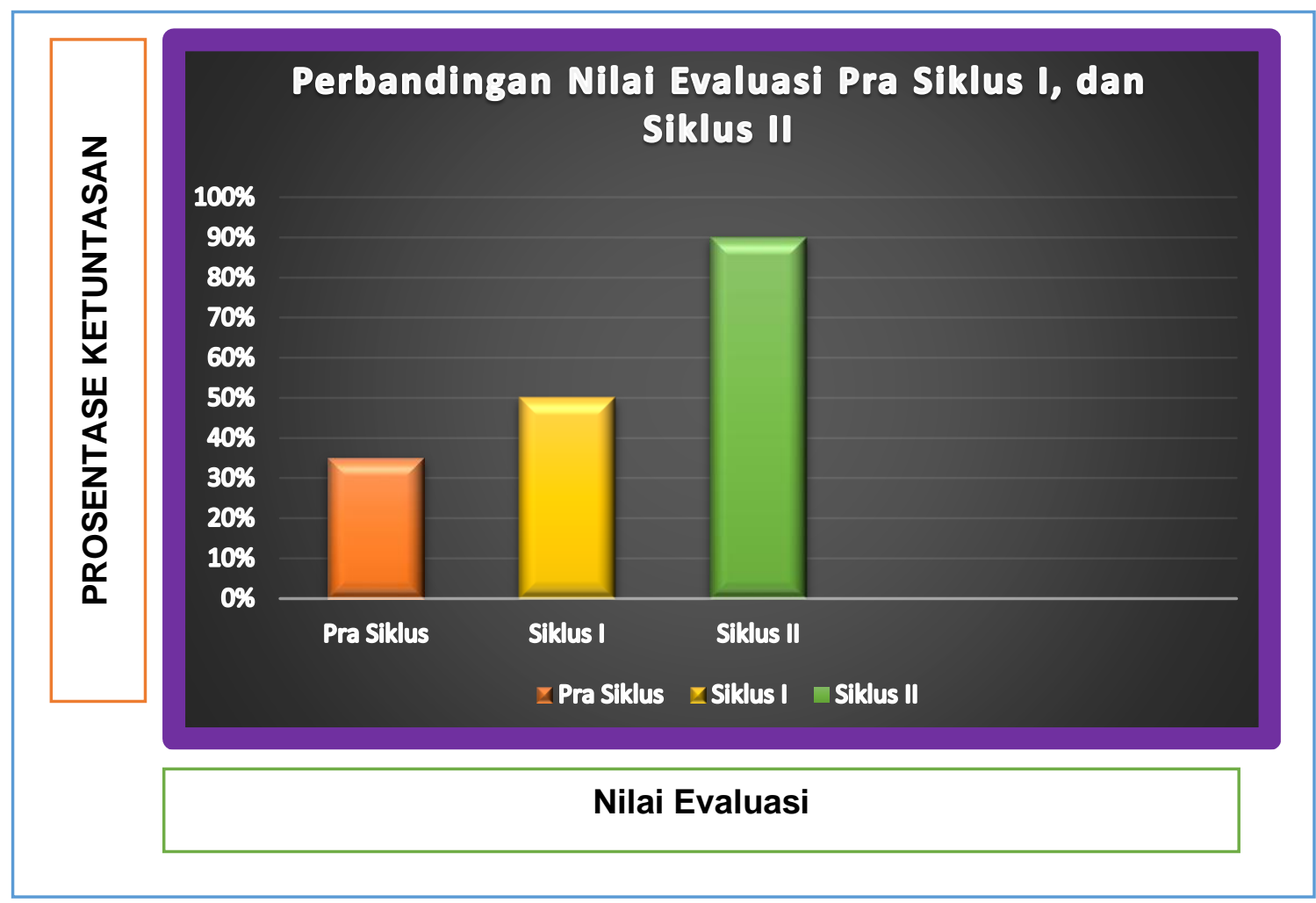

Gambar 2. Perbandingan ketuntasan nilai pra siklus, siklus 1, dan siklus II

Dari hasil nilai ketuntasan di atas dapat dijelaskan bahwa dari 20 siswa yang mengikuti tes evaluasi, yang tuntas belajar adalah 14 siswa. Dengan demikian ada peningkatan dari pra siklus siswa yang tuntas berjumlah $35 \%$, pada siklus I meningkat menjadi $50 \%$, dan pada siklus II siswa yang tuntas meningkat $20 \%$, dari $50 \%$ menjadi $70 \%$. Nilai rata-rata kelas juga mengalami peningkatan yang baik dari 64 menjadi 8. Dari hasil tersebut dapat disimpulkan bahwa mulai dari pra siklus sampai ke siklus I menunjukkan adanya peningkatan pemahaman dan keterampilan siswa terhadap materi pembelajaran.

Dari hasil belajar pada siklus II tersebut dapat dinyatakan bahwa hasil belajar IPA siswa kelas IV SD Muhammadiya Donorejo, Kecamatan Secang, Kabupaten Magelang masih rendah dikarenakan belum mencapai nilai KKM yang telah ditentukan yaitu 70 . Maka perlu adanya tindakan untuk meningkatkan hasil belajar siswa yaitu dilakukan pada siklus III. Hal ini dilakukan agar mengetahui sejauh mana penerapan model Discover Learning tidak hanya meningkatkan tetapi juga mempertahankan hasil belajar peserta didik.

Untuk mengetahui keberhasilan dalam penelitian ini, perlu adanya perbandingan antara nilai hasil evaluasi siklus II dan nilai hasil evaluasi siklus III . Hal ini dapat dilihat pada tabel perbandingan hasil belajar siswa siklus II dan siklus III berikut ini. 
Tabel 3. Perbandingan Nilai Evaluasi Siklus I, siklus II, dan siklus III

\begin{tabular}{|c|c|c|c|c|c|c|c|c|c|}
\hline \multirow[b]{2}{*}{ Predikat } & \multirow[b]{2}{*}{ Nilai } & \multicolumn{4}{|c|}{ Jumlah Siswa } & \multicolumn{4}{|c|}{ Prosentase } \\
\hline & & $\begin{array}{c}\text { Pra } \\
\text { Sikus }\end{array}$ & $\underset{I}{\text { Siklus }}$ & $\begin{array}{c}\text { Siklus } \\
\text { II }\end{array}$ & $\begin{array}{c}\text { Siklus } \\
\text { III }\end{array}$ & $\begin{array}{c}\text { Pra } \\
\text { Sikus }\end{array}$ & $\underset{\text { Siklus }}{\text { I }}$ & $\begin{array}{c}\text { Siklus } \\
\text { II }\end{array}$ & $\begin{array}{c}\text { Siklus } \\
\text { III }\end{array}$ \\
\hline$A$ & $91-100$ & 0 & 0 & 1 & 5 & $0 \%$ & $0 \%$ & $5 \%$ & $25 \%$ \\
\hline $\mathrm{B}$ & $81-90$ & 0 & 2 & 7 & 9 & $0 \%$ & $10 \%$ & $35 \%$ & $45 \%$ \\
\hline C & $71-80$ & 3 & 8 & 6 & 4 & $15 \%$ & $40 \%$ & $30 \%$ & $20 \%$ \\
\hline $\mathrm{D}$ & $<70$ & 17 & 10 & 6 & 2 & $85 \%$ & $50 \%$ & $30 \%$ & $10 \%$ \\
\hline Jumlah Sis & wa Tuntas & 3 & 10 & 14 & 18 & $15 \%$ & $50 \%$ & $70 \%$ & $90 \%$ \\
\hline
\end{tabular}

Berdasarkan data diatas dapat diketahui bahwa pada Pra siklus siswa yang tuntas ada 3 siswa (15\%), siklus I siswa yang tuntas ada 10 siswa (50\%), pada siklus II ada 14 (70\%) siswa yang tuntas, dan siklus III siswa yang tuntas ada 18 (90\%). Dari paparan hasil penelitian dari pra siklus sampai pada siklus III di atas diperoleh data nilai hasil belajar siswa sebagai berikut:

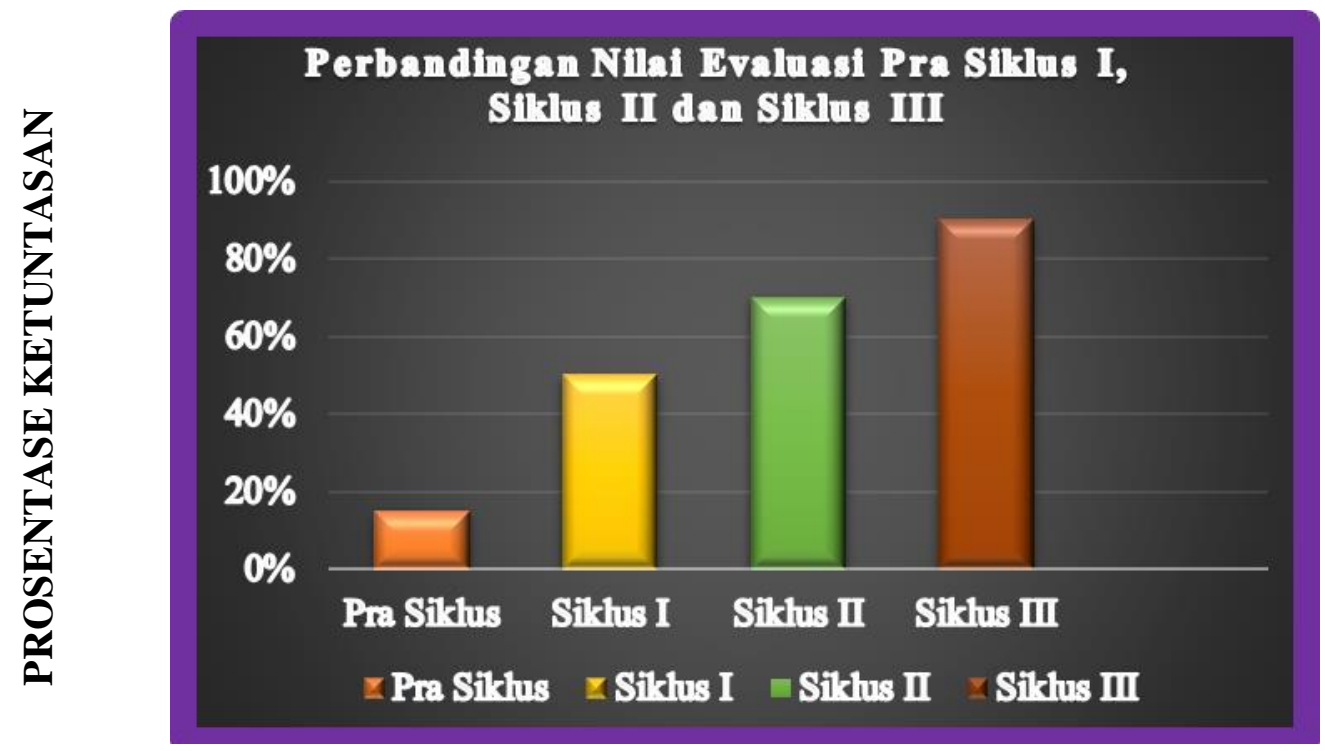

\section{NILAI EVALUASI}

Gambar 3. Perbandingan ketuntasan nilai pra siklus, siklus I, siklus II, dan Siklus III

Dari hasil nilai ketuntasan evaluasi di atas dapat dijelaskan bahwa dari 20 siswa, yang tuntas belajar adalah 19 siswa. Dengan demikian ada peningkatan dari pra siklus siswa yang tuntas berjumlah $15 \%$, pada siklus I meningkat menjadi $50 \%$, pada siklus II siswa yang tuntas meningkat menjadi $70 \%$, dan pada siklus III siswa yang tuntas meningkat $20 \%$ dari $70 \%$ menjadi $90 \%$. Nilai rata-rata kelas juga mengalami peningkatan yang baik dari 79 menjadi 83. Dari hasil tersebut dapat disimpulkan bahwa mulai dari pra siklus sampai ke siklus III menunjukkan adanya peningkatan pemahaman dan keterampilan siswa terhadap materi pembelajaran.

Penelitian ini dikatakan berhasil apabila rata-rata nilai tes hasil belajar siswa pada konsep sifat-sifat di atas nilai KKM, yaitu 70 dan siswa yang mendapat nilai di atas KKM minimal sebanyak $75 \%$. Pada akhir Siklus III diperoleh data: rata-rata hasil belajar siswa 83 dan jumlah siswa yang sudah tuntas ada 18 anak $90 \%$, dan yang 
belum tuntas 2 anak (10\%). Jadi, berdasarkan data pada siklus III Penelitian Tindakan Kelas ini dikatakan telah berhasil.

\section{SIMPULAN}

Berdasarkan penelitian yang telah dilakukan di SD Muhammadiyah Donorejo, Kecamatan Secang, Kabupaten Magelang menunjukkan bahwa hasil belajar siswa mengalami peningkatan. Pada nilai evaluasi siklus I siswa yang tuntas KKM 70 sebanyak 10 siswa (50\%), pada siklus II siswa yang tuntas KKM 70 sebanyak 14 $(70 \%)$ dan siklus III siswa yang tuntas KKM sebanyak 18 (90\%). Jadi, nilai evaluasi dari siklus I sampai dengan siklus III terjadi kenaikan presentase hasil belajar sebesar 8 siswa atau $40 \%$.

Adapun kesimpulannya adalah hasil belajar IPA kelas IV SD Muhammadiyah Donoreji, Kecamatan Secang, Kabaupaten Magelang tahun pelajaran 2020/2021 mengalami peningkatan setelah penerapan metode pembelajaran Discovery Learning.

\section{DAFTAR PUSTAKA}

Depdiknas. (2006). Kurikulum Tingkat Satuan Pendidikan, Jakarta : Departemen Pendidikan Nasional.

Sudjana, Nana. (1995). Penilaian Hasil Proses Belajar Mengajar. Bandung : Remaja Rosda Karya.

Dimyati dan Mujiono. (2006). Belajar dan Pembelajaran. Jakarta: PT. Rineka Cipta

Arief Sadiman. (2008). Media Pembelajaran: Pengertian, Pengembangan dan Pemanfaatannya. Jakarta: Raja Grafindo Persada.

Arsyad, Azhar. (2011). Media Pembelajaran. Jakarta: Raja Grafindo Persada.

Susanto, Ahmad. 2013. Teori Belajar dan Pembelajaran di Sekolah Dasar. Jakarta: Kencana Prenada Media Grup.

Septi U. (2016). Peningkatan Hasil Belajar Ipa Materi Sifat-Sifat Cahaya Melalui Metode Discovery Learning Pada Siswa Kelas V Min Gubug Kecamatan Gubug Kabupaten Grobogan Tahun Pelajaran 2016/2017. http://e-repository.perpus.iainsalatiga.ac.id. Diakses pada 18 November 2020

“__ (2020). Langkah Langkah Model Pembelajaran Discovery Learning https://www.cahayapendidikan.com/langkah-langkah-model-pembelajarandiscovery-learning. Diakses pada 20 November 2020. 